\title{
Conflicts of Interests in the Area of Healthcare Products and Technology. Current State of Affairs and Recommendations
}

\author{
Jean-Paul Demarez ${ }^{1}$, Christian Funck-Brentano ${ }^{2}$, Mathieu Molimard ${ }^{3}$ and the participants of Round Table $N^{\circ} 4$ \\ of Giens XXVII
}

1 Department of Pharmacovigilance, Pierre-Fabre Laboratory, Boulogne-Billancourt, France

2 AP-HP Pitié-Salpêtrière, UPMC, Department of Pharmacology, Paris, France

$3 \mathrm{CHU}$ and Bordeaux University, Department of Pharmacology, Bordeaux, France

Received March 20 ${ }^{\text {th }}, 2012$; accepted June $4^{\text {th }}, 2012$

\section{Keywords:} interest links; experts; impartiality

\begin{abstract}
The handling of conflicts of interest in the area of healthcare products and technology has become a major issue for all of those involved in healthcare. Round Table $\mathrm{N}^{\circ} 4$ at the Giens Workshops 2011 has put forward concrete proposals to clarify and optimise the handling of conflicts of interest.

Conflicts of interest cannot be defined by the individuals consulted or applying for funds since each institution, whether public or private, that puts out a call for projects or that requests advice, analyses or expert testimony in the healthcare field has different degrees of what it defines as a conflict of interest, depending on the context of the proposal or specific request that it puts out. In contrast, each individual has ties of personal interest that can and must be openly disclosed. The ties are much more diverse than what is commonly found in the conflict of interest statements of large institutions operating in the healthcare field and are not limited to financial and operational ties between companies and individuals. In addition, the statements are difficult to manage because of their sheer number.

The Round Table recommends that each individual should openly disclose all of his or her ties of personal interest in a Single Statement of Ties of personal Interest (SSTI). The SSTI would be updated regularly and accessible on line. Each institution could then determine whether or not the reported ties represent a conflict in the context of the mission proposed. Each institution could publish in advance the conditions that would give rise to a conflict and, in this way, an individual could refrain from applying for the mission.

Other practical approaches to handling conflicts of interest were put forward.
\end{abstract}

Abbreviations: see end of article.

\section{Background and definitions}

Conflicts of interest in the healthcare field are a preoccupation not only for public opinion but also for public authorities. The participants in the present Round Table therefore set out to assess the current state of affairs and to put forward recommendations in the specific area of healthcare products and technology.

Professionals, pharmacists or physicians, involved in the area of healthcare products are, by virtue of the various positions and social roles that they may occupy or fulfil, often placed in situations that can give rise to conflicts of interest. They may be, at the same time, involved in patient care, as hospital practitioners or in private practice, professors at the university level or in the post-graduate setting, researchers in public or privately funded institutions, consultants or investigators working with pharmaceutical firms, experts mandated by public commissions, or members of commissions.

All of these social activities necessarily lead to ties of personal interest. For many reasons, both practical and symbolic, the first ties that come to mind are monetary ties. In most of the situations mentioned above, the professional may receive financial compensation in exchange for his or her services, and the variety of terms employed, salary, stipend, fees, grant, bonus... reflects the diverse nature of the ties. The question of conflict of interest is not however limited simply to economic aspects. The professionals concerned have, as do most people, other ties that can influence their choices.

\footnotetext{
* For the list of participants, see end of article.
} 
These may derive from their family or personal life, from their membership in political or trade associations, as well as philosophical or religious groups, from intellectual or professional affinities they may have developed, from their background or career expectations, from the firms they work for... in short, from everything that pertains to a person's particular path of life.

Ties of this nature are inherent to life in society, and very few people are free from such ties, or can free themselves from them.

Under certain circumstances, such ties can, at a given time, potentially or indeed effectively give rise to a "conflict of interest".

Numerous definitions have been suggested for the expression. The participants in the Round Table came to the agreement that a conflict of interest is a situation in which a professional does not act, or may be suspected of not acting, in accordance with the interests that he or she is, from a social standpoint, supposed to defend or be responsible for, but acts instead to further his or her own private interests or those of a third party.

This definition is therefore to be placed in the context of healthcare products and technology, which is the subject of the present analysis.

\section{Specificities of the present context}

Before they can be placed on the market, healthcare products are subject to decisions successively taken by the competent authorities or agencies with regard to marketing authorisation, to the policy of reimbursement by national or private health insurance, to their conditions for use, and to the various guidelines that set out the therapeutic strategies in which they can be used.

The various decisions are made after consultation with commissions and on the advice of experts. The members of the commissions and the experts called upon are chosen among professionals who are recognised as having the knowledge necessary to meaningfully assist decision-makers.

The term "independent" is currently used to define the main quality that characterises a "good" expert. The term proves to be inaccurate in view of the numerous ties of personal interest mentioned above. No expert can in fact be free from such ties or provide guarantees that he or she is free from them.

An expert is expected to be impartial rather than independent.

In the interest of the general public, as well as in the interest of patients, the expert testimony provided must not be biased by considerations or interests that are foreign to the mission of the expert, and decisions taken on the basis of the testimony must not be tarnished by partiality.

The public authorities have long been concerned by the question of conflicts of interest, particularly among members of the commissions involved in evaluating healthcare and medicinal products, as well as among experts in the field, and have set up a system of regular declarations. The principle of regular declarations seemed to be sufficient to detect conflicts of interest and to draw the consequences of their potential presence. The french Food Safety Agency and Health Products (Afssaps, became since 2012 National Security Agency of Medicines and Health Products [ANSM], french High Authority of Health (HAS) and the french National Cancer Insitute (INCa), for example, have developed inhouse procedures, in addition to specific questionnaires, that are supposed to provide adequate checking and handling of conflicts. All of these measures, however, add up to a heterogeneous, complicated and redundant system with the result that the experts called upon by one or another of the structures must make unnecessary and repetitive declarations. The heterogeneity of the overall system does not plead in favour of its effectiveness.

The ultimate goal of the present Round Table is to put forward a proposal for a Single Statement of Ties of personal Interest (SSTI), which will simplify and improve the disclosure process, and to propose rules on how those requesting advice and expert testimony might use the SSTI to determine whether or not the ties represent conflicts of interest and, if so, how such conflicts should be dealt with.

If the personal ties, not only of experts, but also those of decision-makers are known, it should be possible to avoid situations where one or the other is under the influence of a conflict of interest at the time of carrying out the mission or fulfilling the role entrusted to him or her.

The objective of general interest pursued here goes well beyond the scope of how administrative decisions are taken and of how this or that healthcare product is handled. The objective extends to healthcare spending, therapeutic advances and appropriate use of medicines, the information provided to professionals and to the public, and to questions of how healthcare policy is decided.

The question of conflicts of interest is therefore likely to extend to all those involved, including journalists writing for the specialised press or the general public, who play a part in informing healthcare professionals, as well as the public.

\section{The obligations of the expert}

If we focus the present analysis on an expert mandated by this or that institution, keeping in mind that it is natural to have ties of personal interest, several practical considerations come to light. The expert is the best judge of whether or not, to his or her knowledge, there is a potential conflict between one of his or her personal ties and the interests of the mission that he or she has been entrusted with. No one is forced to accept a mission as an expert.

The analysis should not however stop there. It is up to the expert to declare to the institution that plans, or indeed that may be planning to mandate him or her, all financial ties, both direct and indirect, consequential or secondary, as well as any other ties that 
he or she believes could lead to a conflict of interest. The list of ties could be both standardised and exhaustive (see below).

The institution then examines the ties declared by the persons it plans to mandate, and it is up to the institution to decide, at the time when it mandates the expert, whether or not there is a conflict, positive or negative, major or minor. The institution may also ask a candidate to clarify his or her situation, in application of the right to be heard, before it draws the necessary consequences.

The declarations made by the professional who is a candidate for the role of expert should be accessible and public, and should be updated when a significant change is made to the list of ties the candidate has previously declared.

The ties of personal interest should be stated in such a way that they are intelligible and make it possible to determine whether or not certain ties represent or could represent a conflict of interest in the particular context of the mission proposed.

It should be noted that a personal tie might give rise to a conflict of interest in a particular situation but not in another situation.

A personal tie may lead an expert to attempt to influence a decision in order to further the interest of third party, which we will call a positive conflict. A personal tie may also lead an expert to hinder the interest of third party, which we will call a negative conflict. Not all personal ties have the same impact on the expert's situation and, among the stated personal ties, some may be considered as major conflicts and others as minor conflicts.

In order to provide an exhaustive statement of his or her ties of personal interest, the candidate may need to consider ties that concern his or her private life. There should be a section that allows him or her to do so without infringing on his or her privacy with regard to those for whom the statement is intended, as well as anyone who could potentially read the statement, since the latter is public.

As concerns the specific case of experts who are called upon in the context of, or at the request of competent consultative commissions in the area of healthcare products and technologies, the participants in the Round Table have put forward five proposals:

- a single statement, drawn up by each expert, listing his or her ties of personal interest at an Internet address using a standard document in the form of a table (Single Statement of Ties of personal Interest or SSTI) with sections containing information on the nature, the type, the duration and the scope of the tie(s) [table I];

- the institution concerned should examine the ties prior to mandating the expert, and may be led to reject the expert. Before rejecting the expert, the institution may choose to go further into the question, and the expert's right to be heard should be included in the process;

- several experts should be mandated to work together on the same mission. The collective approach seems to be an excellent means to ensure impartiality;

- the various public institutions concerned should create a question and answer section related to conflicts of interest, accessible to experts, which would provide them with points to consider that could potentially lead them to refrain from applying for a particular mission. The section could be presented as a collection of "precedents", based on actual cases;

- Sanctions for experts who are intentionally forgetful. An administrative court could annul decisions or actions that are taken based on the opinion of an expert who has made an incomplete statement, whether intentionally or unintentionally.

Educational programs, training and evaluations should be set up by the public authorities, learned societies and representative associations in order to ensure that the healthcare professionals concerned give careful consideration to the problems inherent to their ties of personal interest.

\section{The SSTI}

All financial ties could be declared using the SSTI (table I), including salaries, fees received as a consultant or expert, or as an investigator taking part in medical research, compensation or reimbursement of expenses as a member of a committee or commission, as a participant in a congress or as a guest speaker, dividends received as a shareholder or royalties as a patent-holder...in particular since the SSTI table seems to be a "catch-all" in this regard.

The table has however also been designed to allow any nonfinancial ties, direct or indirect, to be disclosed, and at the outset of this analysis we acknowledged the great diversity of such ties.

The SSTI could be consulted prior to mandating an expert and, in addition, it could be consulted at the start of any session of a commission, as concerns the members present, in order to check for specific ties, by posting for example, for the attention of all participants, ties identified as conflicts of interest.

The SSTI could also be used by any expert who has been approached or who hopes to be, any healthcare professional, any decision-maker in the matter, any member of a learned society or patient association, and any journalist working in the field, whether intended for public institutions, learned societies, press organisations, or the general public.

Using the SSTI, it should be possible to determine the nature (positive or negative) and the extent (major or minor) of the potential or proven conflict of interest before the institution takes its position.

In most cases, the question of a conflict of interest is resolved by the expert him or herself, who refrains from applying, or by the institution, which rejects the application. There are however scientific disciplines or areas, in particular orphan diseases, where only a limited pool of experts are available. Going outside the pool raises the risk that the expert testimony will be of poor quality, with the added risk of biased testimony. This situation will clearly have an impact on considerations as to what degree of conflict of interest is acceptable. The degree to which a conflict of interest is considered acceptable will be inversely proportional to the number 


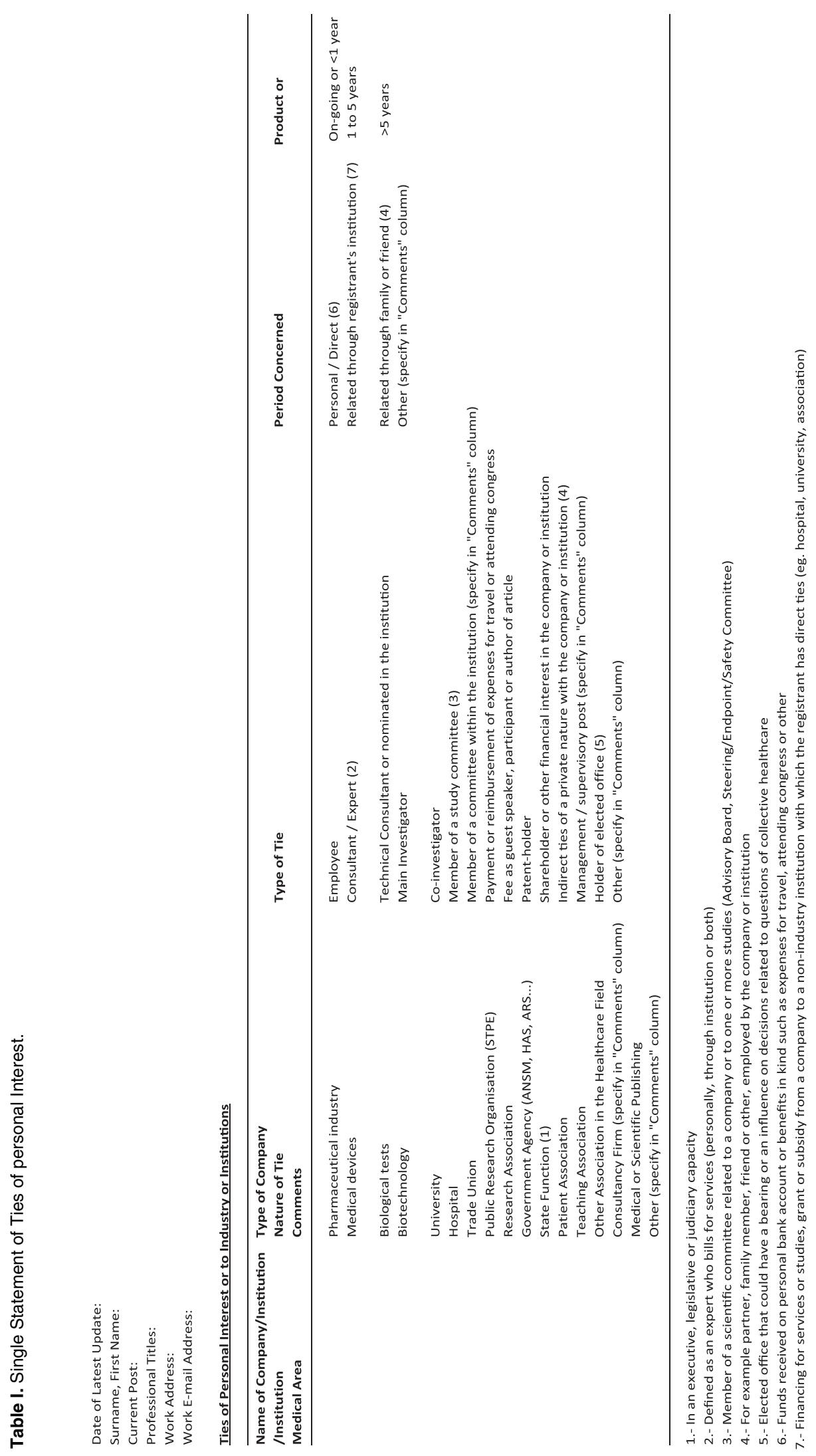


of competent experts who are available to be mandated. In this situation, it is up to the institution requesting expert testimony to decide how it will handle testimony from experts who have conflicts of interest. The experts may, for example, provide their testimony, but be excluded from taking part in the final decision. The final decision will be made based on the opinion of a body of persons who have taken into account the testimony provided by the expert in question.

Within the communal context and using a common framework for interpretation, as much for the experts as for the institutions, it is up to each institution to ensure that choices are made in a transparent manner, and, if necessary, to justify them when they involve acceptance of conflicts of interest.

\section{Sanctions for undeclared ties}

The statements are intended to be complete, sincere and truthful. A statement that does not contain any ties of personal interest would not be credible. Thus an expert who has declared all of his or her ties can be considered to be in the clearest situation with regard to the public authorities: "all ties declared - expert protected".

Nevertheless, in the context of an inspection, or if a decision is questioned, or indeed denounced, a situation could arise in which the expert is not found to have made a full disclosure, or has failed to fully update his or her statement.

The expert may be considered to be in good faith, and the shortcoming considered as the result of an omission, absent mindedness or an error.

It is nonetheless certain that, if the facts are confirmed, the expert may be subject to disciplinary sanctions imposed by the board of the professional association he or she belongs to. The fact that the mistake was unintentional does not exonerate the expert.

An incomplete statement that results from intentional falsification of the facts is similarly subject to disciplinary sanctions, but also constitutes a criminal offense and may be subject to criminal prosecution.

The action may be seen as an act of forgery or of taking unlawful advantage, indeed, depending on the information available, it may be seen as conspiracy to commit fraud.

An administrative decision that is taken based on testimony from experts whose compliance with the rules of full disclosure is questionable, whether this is intentional or unintentional, may be overturned by an administrative court as it constitutes a violation of the legal requirements for carrying out administrative acts.

\section{Experts and assessors}

Decisions by the competent authorities with regard to healthcare products and technologies are taken after an initial phase involving analysis of the technical or scientific aspects.
Two categories of persons are likely to participate in the initial phase: internal assessors, who are salaried employees of the competent authorities, and external experts, who are chosen based on their reputation in the area concerned. The external experts most often come from the hospital or university-hospital setting.

It goes without saying that internal assessors cannot have economic ties (the only ties that are readily distinguishable) with organisations other than the government administration that employs them, unless they have a special derogation from their hierarchical superiors.

Assessors are the opposite of external experts in terms of advantages and disadvantages. They do not have any economic ties that could bias them in their work, which is an advantage, as opposed to experts, for whom this possibility exists.

Experts acquire senior status through experience gained in the course of a sometimes long scientific career, while assessors are in most cases junior. Once assessors have gained experience, they may be tempted to capitalise on it in an organisation other than their original government administration.

Assessors may also hope to build a career profile starting with their initial post, which guarantees them a salary, but the same is not true for external experts. Indeed, activities as an expert are not taken into account in the careers of professionals who fulfil this role. In addition, most often the financial compensation paid by government administrations that have recourse to experts does not reflect the actual work carried out (considered almost as volunteer work).

In view of this paradoxical situation and in conclusion to their discussions, the participants in Round Table $\mathrm{N}^{\circ} 4$ consider that:

- on the one hand, internal assessors should have the possibility to develop their experience within their government administration, with levels of remuneration that discourage the departure of senior assessors, since all external financial ties are prohibited. This will help to strengthen the system of internal assessment,

- on the other hand, the situation in which external experts carry out their role as if it were volunteer work must disappear. Activities as an external expert should be valorised and incorporated into the career profile of the persons concerned, at the same time as the possibility of financial ties. The extent to which these ties influence their potential activities as experts will, moreover, be mitigated by consulting the expert's SSTI.

\section{Participants.}

Marion Bamberger (Bristol Myers Squibb), François Bassompierre (AP HP, DRCD, Paris), Paul Benkimoun (journal Le Monde, Paris), Driss Berdaï (CHU, Bordeaux), Jean-François Bergmann (Hôpital Lariboisière, Paris), Pierre-Henri Bertoye (ANSM, exAfssaps), Nathalie Billon (Laboratoire Sanofi-Aventis), Frédérique Brudon (Fédération des spécialités médicales, Villeurbanne), Gaëlle Courtois (AP HM, Marseille), Claudie Damour-Terrasson (journal Edimark, Paris), Rima De Sahb (Laboratoires MSDChibret), Muguette Depardon (HAS, Saint Denis la Plaine), 
François Faurisson (Eurordis), Alain Francillon (Laboratoire Novartis), Jean Gardette (ANSM, ex-Afssaps), François Garnier (Laboratoire Pfizer), Véronique Lamarque-Garnier (Laboratoire Pfizer), Catherine Lassale (Leem), Claire Le Jeunne (AP HP, Hôtel Dieu, Paris), François Montastruc (CHU, Toulouse), Nicholas Moore (CHU, Bordeaux), Joël Moret-Bailly (Université de Lyon, Sainte Foy lès Lyon), Christine M'Rini (Institut Mérieux), Marc Rodwin (Suffolk University Law School, Boston, USA), Myriam Zylberman (Laboratoire Lilly France).

\section{Conflicts of interest. None.}

Abbreviations. Afssaps: french Food Safety Agency and Health Products; ANSM: french National Security Agency of Medicines and Health Products; HAS: french High Authority of Healht; INCa: french National Cancer Insitute; SSTI: Single Statement of Ties of personal Interest.

Correspondence and offprints: Jean-Paul Demarez, Department of Pharmacovigilance, Pierre-Fabre Laboratory, 45 place Abel Gance, 92654 Boulogne Cedex, France.

Email: jean.paul.demarez@pierre-fabre.com 